\title{
Allocating government budgets according to citizen preferences: a cross-national survey
}

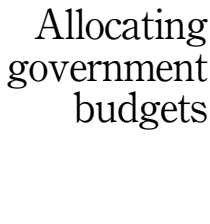

Nils Soguel

IDHEAP-Swiss Graduate School of Public Administration, University of Lausanne, Lausanne, Switzerland

Eugenio Caperchione

Department of Economics, University of Modena and Reggio Emilia, Modena, Italy, and

Sandra Cohen

Department of Business Administration, Athens University of Economics and Business, Athens, Greece

\begin{abstract}
Purpose - The goal of this exploratory study was to investigate if, when asked to state their preferences for the allocation of public monies toward broad governmental functions, individuals state them at random or if their choice follows some rational pattern that can be traced using explanatory variables.

Design/methodology/approach - The paper presents the results of a survey conducted in Greece, Italy and Switzerland where the contingent allocation method was applied to a hypothetical allocation scenario of public monies to the functions of the government.

Findings - Findings based on 428 answers revealed that individuals were able to state their preferences for the various functions of the government as well as discriminate between the relative utility of each task and that the country context and personal characteristics significantly influence the respondents' allocations.

Originality/value - From a policy perspective, understanding citizen preferences in budget allocation may help governments rationalize the spending of public money.

Keywords COFOG, Functions of government, Budget allocation, Public administration, Survey method

Paper type Research paper
\end{abstract}

\section{Introduction}

Official statistics have dramatically improved in terms of reporting how much governments spend on providing public services, thanks in particular to the Classification of the functions of government (COFOG) and improvements in governmental accounting systems toward accruals. The United Nations' COFOG is a consistent and widely recognized classification for categorizing government transactions (see e.g. IMF, OECD, Eurostat). Additionally, improvements in accounting systems enable governments to represent and disclose the substance of transactions more faithfully. Both schemes allow for an increasingly accurate measurement of the financial costs of the various functions that governments actually perform. But neither make it possible to measure the extent to which citizens are satisfied with the way their contribution to a governmental budget is allocated to the various functions of government (FOGs).

Following Welch et al. (2004), Royo et al. (2011) consider that there is a gap between public expectation and perceived governmental performance. This gap leads to a decline of public

We are indebted to all those who took the time to participate in the survey; to Sandro Brunelli for his contribution in administering the questionnaire; to the editor and the two anonymous reviewers for their insighful suggestions; to Yves Ammann for his computing assistance; and to Michelle Bailat-Jones for her editing assistance.

Received 7 August 2019 Revised 10 December 2019 13 March 2020 28 April 2020 Accepted 1 May 2020 
trust in government. The current trend toward more participative approaches attempts to reverse this decline and to address concerns about what is called the "democratic deficit" (Walters et al., 2000). Most attempts have been made on a small, almost marginal, scale. Participatory budgeting, for instance, allows citizens to identify, discuss and prioritize very specific public spending projects, usually at the local level. Other, more bureaucratic, techniques have also been considered to improve efficiency in the public sector. For instance, program budgeting enables a better understanding of the allocation of resources. It also facilitates the assessment of program performance by comparing outputs with predefined goals and targets. As for cost-benefit analysis, it weights the benefit of a given infrastructure project or public policy against its costs. Although more general, a public policy evaluation focuses on a single policy concern. At the end of the day, the prioritization of policies is still a political process, mainly made by politicians without direct citizen involvement. Arguably, however, when citizens vote for a political party they should be aware of its political program and the priorities it promotes. Thus, their vote is an indirect general approval of an overarching political agenda, but it is just limited to that: it is not an expression of specific public spending preferences.

This paper is rooted in the growing stream of literature dedicated to participative approaches in government. Indeed, a variety of mechanisms have already been designed. For example, Rowe and Frewer (2005), focusing on the UK and the United States, identify more than 100 different types of public participation or engagements mentioned in the literature and technical reports. Smith (2005) identifies 57 democratic innovations from around the world, defining them as "formal methods for involving citizens in the political decision-making process". Although these mechanisms belong to the same movement, they nevertheless represent very different models of public participation. However, what unites them is the fact that they focus on relatively small-scale projects or policies. Consequently, these mechanisms do not enable overall trade-offs between the main functions provided by a state or central government.

To the best of our knowledge, the literature has not yet come up with a scheme that would allow citizens to tailor an overall government budget to their needs and benefits. This exploratory study thus innovates in the sense that it aims to express citizen preferences for public services in terms of government budget shares. It also methodologically innovates in transposing the basic idea of the contingent valuation method (CVM, Mitchell and Carson, 1989) to the field of budgeting. By doing so, the CVM becomes a contingent allocation method (CAM). CAM relates to budget games (Bondonio and Marchese, 1994) as it uses a survey instrument where a sample of respondents are facing a hypothetical scenario that empowers them to state their preferences and allocate public funds to the main FOGs is expected to perform. The scenario used dictates that they have to consider only the benefit (or the utility) they place on the role played by the Government and other public entities. Thus, the empirical goal of the research was to assess if citizens are able to state their preferences should they be consulted on the details of budget allocation. And, if this is the case, to investigate whether the statement is random or, on the contrary, follows some rational pattern that can be traced using explanatory variables involving personal characteristics and the country context. For that very reason, we tested the potential of the CAM in a multi-country setting, using a convenient sample. More specifically, we tested how citizens differentiate between the various FOGs according to the importance of the provided benefits in general and for their country in particular.

Section 2 provides the theoretical background by briefly surveying the normative and positive literature on public budgeting. It concludes with this paper's research question. The way the survey was designed is described in Section 3, including the empirical setting, the choice of data collection and the contents of the questionnaire. The full questionnaire and the database are available upon request. Section 4 is a descriptive presentation of the survey results. Section 5 provides further analysis by modeling respondent allocations in order to highlight influencing factors and assess the internal validity of the budget allocation. Section 6 concludes the paper. 


\section{Literature, theoretical background and research question}

In 1940 already, (Key, 1940) complained that too many efforts were dedicated to the organization and the procedure for budget preparation and too few to the aim of public budgeting, i.e. "the allocation of expenditure among different purposes so as to achieve the greatest return" (p. 1137). According to Key, the methodological question is: "On what basis shall it be decided to allocate $x$ dollars to activity A instead of activity B?" (p. 1138). In his seminal paper he reviews the historical solutions offered in response and highlights their shortcomings, short-sightedness and partiality: "Efforts to ascertain more precisely the relative 'values' of public services may be though fruitless because of the influence of pressure groups in determination of the allocation of funds" (p. 1143). In a purely normative way, Lewis (1952) is the closest to answer Key's question. For him, "Budget decisions must be made on the basis of relative values [...] The results must be worth their cost" (p. 42). "The benefits derived from any expenditure must be worth their cost in terms of sacrificed or displaced alternatives" (p. 45). Lewis (1952) notes that "the ideal of democracy is that the desires of the people, no matter how they are arrived at or how unwise they may be, should control the actions of government" (p. 45). This is in line with the fundamental theorem of welfare economics: public decisions should be made on the basis of their impact on individual welfare, and individuals are best placed to decide what this impact is (Layard, 1972, p. 10).

The disconnection between the level of service provided and the amount preferred by citizens is one form of what is sometimes referred to as the "public goods problem". The public goods problem is a public management problem which arises when there is a need for citizen participation in resource allocation. When there are no important disagreements, public managers may feel comfortable imposing their preferences without investing in a citizen participation mechanism. However, passionate disagreements may arise when decisions are complicated and involve high future costs. This is when knowledge of the "true" preference structure of an informed citizenry seems most valuable (Robbins and Simonsen, 2002). Citizen involvement in resource allocation decisions can take place in many ways. In most cases through public hearings, citizen committees and advisory boards (Simonsen and Robbins, 2000).

From another stance, Dahl (1971, p. 1) argues that the continuing responsiveness of the government to the preferences of its citizens is a key characteristic of a democracy. Especially in relation to social spending, Soroka and Wlezien (2010, p. 128) argue that when the public wants more social spending, policymakers usually provide it.

Starting with Wildawsky (1961), other contributions take a more positive and empirical stance by integrating institutional arrangements in the analysis. Institutional arrangements include the formal and informal rules that govern the budget process. They also include the division of roles and responsibilities among the various actors at each stage of the process. They demonstrate how "budget institutions shape and regulate the policy and process of generating and allocating public resources for carrying out government functions" (DablaNorris et al, 2010, p. 4). However, when analyzing the relationship between budget institutions and fiscal outcomes, these contributions focus on the impact on budget deficits and debt or on specific categories of expenditures. The (in)ability of institutional arrangements to efficiently allocate budget resources is central to the public choice literature dedicated to budget incrementalism and preferences of interest groups in comparison with those of the median voter (Downs, 1957; McNutt, 1996).

In order to circumvent these identified inefficiencies, new budget methodologies were proposed: Planning-Programming-Budgeting-System (PPBS), Zero-Based Budgeting (ZBB), Program Analysis and Review (PAR), Modified Budget System (MBS) or, more recently, accrual output based budgeting (AOBB) (Carlin, 2003). Compared to incrementalism, these methodologies expand budget flexibility as well as the leeway of public decision-makers (e.g. finance ministers and line ministers). However, they are not designed to directly integrate citizen preferences and requests for the various government functions.
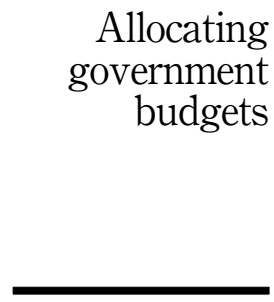
More recently, new schemes have been designed to directly involve citizens in the budgeting process - and among them participatory budgeting. Political and social actors have different motivations for promoting and engaging in participatory budgeting. Participatory budgeting has been mainly implemented in local governments in order to build a base for political support, achieve a more equitable support for scarce resources, foster public learning and promote transparency in the public sector. On the other hand, citizens are willing to take part in these initiatives in order to increase their access to decision making, have access to information and improve the quality of services provided (Wampler, 2007) as shown by some recent initiatives in OECD countries or local initiatives (see e.g. Cologne, Germany: https://buergerhaushalt.stadt-koeln.de). Similarly, in 2006, the International Social Survey Program focused on the role of government and included questions about various areas of government spending (http://issp.org/menu-top/home/).

However, these latest attempts are limited to specific projects. Relying more on citizens to define the main lines of the overall budget is something that has not been suggested yet, although the idea flows directly from welfare economics, as mentioned before. But in order for that to happen, it should be proven that individuals allocate budget resources according to their preferences and that they can differentiate their demands for various government programs or tasks. Both Lewis and Layard's normative views, though theoretically wellfounded, would only be of little help if, in practice, individuals were unable to deal with the complexities of the issue. In particular, because of their limited capacity to process the information, as some authors and politicians fear (Walters et al., 2000). Citizens are also likely to adopt strategies to lighten the task. They would take recourse in heuristics, simplified decision rules or they would even provide a random answer to the allocation problem. The existing literature on participatory budgeting has not yet addressed the issue of whether, when given the possibility to take part more extensively in the budget allocation process, citizens would avoid randomness and would somehow rationally state their preferences. In response to all this, we defined the following question:

When asked to allocate the overall budget, do individuals state their allocation purely at random or, on the contrary, do their answers follow some rational pattern?

This main question is investigated using three more specific research questions:

$R Q 1$. Are individuals able to discriminate their allocation between the various tasks, i.e. do allocations statistically differ? [1]

$R Q 2$. Do individuals avoid simplifying their task by not anchoring their answers on some piece of information provided by the questionnaire?

RQ3. Can the allocation be, at least partially, explained by some personal and sample characteristics?

Gathering evidence on the above research questions might provide a useful starting point for a possible expansion of participatory budgeting not only in local governments but also at the central government level.

\section{Methodology and survey design}

The methodology used in this study was derived from the CVM. Traditionally, CVM is used to measure individual preferences for non-market goods (Champ et al., 2003). The technique was originally developed to value environmental amenities taking inspiration from marketing studies but has eventually been opened to other domains as well (Carson, 2011). Nevertheless, its application to government decision-making has been limited to cost-benefit studies in areas like environmental amenities, cultural assets or public health. In CVM respondents are confronted with a hypothetical situation where they are asked to state their 
willingness to pay in order to benefit from a hypothetical improvement or to avoid a hypothetical deterioration of an existing situation. Alternatively, respondents can be questioned about their willingness to accept a compensation either to forgo a hypothetical improvement or to suffer a hypothetical deterioration. The contingent approach is a very versatile methodology since it utilizes hypothetical scenarios. But precisely because of that, it is also prone to various biases, although this is still a debated issue (Hausman, 2012; Carson, 2012). This means that recommendations made to ensure the validity of the estimates must be kept in mind (Arrow et al., 1993). In so far as these recommendations - published in the US Federal Register - are followed, the US government and courts are now permitted to use CVM-based estimates as a basis for their decisions.

Here we take advantage of the versatility of the technique and adapt the methodology to the budgeting process. The technique becomes a contingent method to allocate budgetary resources. The CAM confronts individuals with a hypothetical situation where they have full power to allocate the budgetary resources of the entire government (100 units in total) to a defined set of 10 FOGs. Thus the aim is not, as in CVM, to pin down a trade-off between a given amenity to be valued and other goods and services under an individual budget constraint (i.e. a marginal rate of substitution). The aim of CAM is to pin down the trade-off between the defined FOGs within a defined volume of budget resources. Therefore, respondents are explicitly required to allocate the budget according to the relative utility of the various FOGs. They are instructed that the number of units allocated to the function should correspond to the importance that they would place on the role the government should play on that matter. The exact wording used was as follows:

"Imagine you have the power to allocate all budgetary resources of all the various governments in your country (where you live) to the different functions that the state must fulfil. In this capacity, you have the power to centrally allocate all receipts from all governmental levels (central, regional, local, etc.) as well as social security. Your task is simplified since you are not accountable to anyone and you alone may decide how to allocate the budget. For simplicity, let us assume that the resources at your disposal total 100 units; you may also consider this to be 100 monetary units or $100 \%$. You must allocate these 100 units to the various overall functions that the state must fulfil. The number of units you allocate to a function must correspond to the importance - in other words, the utility - that you grant to the State in that particular matter. Let us imagine that you allocate 15 units to a given function and 28 to another one. This would mean that you place a higher importance and thus grant more resources to the function that is given 28 units. The table on the right classifies the functions of the state across ten areas. To help you, it also includes an indication of the policy concerns for each function."

Moreover, respondents were notified that there were no right or wrong answers to the way the units would be allocated, that it was their personal view that is interesting and that all answers would remain absolutely anonymous. The respondents had to complete a table with how they would allocate their 100 units to the ten FOGs. Additional information described the scope of each function, i.e. the various subfunctions included in the COFOG classification [2]. Follow-up questions based on the wording used in the Standard Eurobarometer were also asked to help identify respondents' personal characteristics. Most of this information was used to explain respondent allocations (see Section 5).

The questionnaire was designed to be administered in a classroom or similar circumstances. It was deliberately kept short so it could be printed on an A3-sheet of paper, to show respondents that it would not take them very long to fill out. As a matter of fact, it was designed to take 15-20 minutes to complete.

Since the aim was also to identify any possible influence of national context (i.e. countries), the questionnaire had to be disseminated in different countries. As a result, the questionnaire was administered to convenient samples in three countries: Greece, Italy and Switzerland.

\section{Allocating government budgets}


When setting up the questionnaire, special attention was paid to the design of the contingent scenario and the allocation instructions in order to keep them neutral with regards to the various national contexts. The questionnaire was originally developed in English and then translated into Greek, Italian and French [3].

Respondents were civil servants, entrepreneurs, head teachers or students taking Master's and advanced studies courses in public administration, management, economics, accounting and finance at Universities in Athens, Modena and Reggio Emilia, Rome, Milan and Lausanne. They were surveyed between February 2016 and July 2017 [4]. The convenient sampling method is appropriate, regarding both the investigated countries and the individual respondents, given the purpose of the survey. Indeed, the concern is to get indicative results from a heterogeneous sample. Therefore, sampling bias is not an issue, since the convenient character of the sample by definition is not representative of the three countries' population. Nevertheless, all the respondents are citizens of an age to vote, pay taxes and are generally active in the society. Therefore, they could be expected to be both suitable and capable of expressing their government budget allocation preferences. Each respondent filled in the questionnaire individually and there was no cooperation among participants. For that, a member of the research team was present during the questionnaire completion.

\section{Survey results}

More than 120 observations were gathered from each country $(N=133$ in Greece, $N=126$ in Italy and $N=169$ in Switzerland). Altogether, 428 persons agreed to participate in the contingent allocation process, answer the questionnaire and state how they would allocate the budget. Statistically speaking, the sample size was large enough to address the research questions.

Table 1 presents the descriptive statistics regarding respondent allocations by country subsample. Functions are ranked according to the mean allocation computed over all the available observations (Overall). The three FOGs to which the largest slices of the budget were allocated are in decreasing order of magnitude: Education, Health, Social protection. Regardless of the country subsample, each of these three functions was allocated more than $10 \%$. Depending on the subsample, Education and Health may swap ranking. For the rest of the FOGs, the ranking varies between subsamples, with a standard deviation becoming more important compared to the mean. Overall the FOGs to which the smallest slices were allocated (i.e. share is equal or smaller to 7\%) are: General public services; Recreation, Culture and religion; Defense. The allocations are often relatively similar between subsamples. However, mean preferences may differ for some FOGs. For instance, preferences for Defense were twice as high in the subsample of Greek respondents $(8.2 \%)$ than in the Swiss (4.7\%), with the

Table 1. Respondent allocations Defense

\begin{tabular}{lrrrrrrrr}
\hline & \multicolumn{2}{c}{ Overall } & \multicolumn{2}{c}{ Greek } & \multicolumn{2}{c}{ Italian } & \multicolumn{2}{c}{ Swiss } \\
Function & Mean & SD & Mean & SD & Mean & SD & Mean & SD \\
\hline Education & 16.3 & 5.9 & 17.1 & 7.3 & 15.3 & 4.8 & 16.3 & 5.4 \\
Health & 16.0 & 5.5 & 17.8 & 6.3 & 16.5 & 5.8 & 14.3 & 4.0 \\
Social protection & 12.2 & 5.5 & 10.3 & 4.8 & 11.7 & 4.5 & 13.9 & 6.1 \\
Economic affairs & 9.6 & 4.8 & 9.7 & 5.4 & 9.1 & 4.5 & 10.0 & 4.5 \\
Environmental protection & 9.2 & 4.6 & 8.1 & 3.5 & 10.6 & 5.7 & 9.0 & 4.2 \\
Public order and safety & 8.8 & 4.2 & 8.9 & 4.0 & 10.1 & 4.9 & 7.8 & 3.4 \\
Housing and community amenities & 8.2 & 3.8 & 7.7 & 4.1 & 7.5 & 3.4 & 9.1 & 3.6 \\
General public services & 7.0 & 4.1 & 6.1 & 3.9 & 7.4 & 5.0 & 7.4 & 3.3 \\
Recreation, culture and religion & 6.4 & 3.5 & 6.1 & 3.7 & 5.4 & 3.1 & 7.4 & 3.5 \\
Defense & 6.3 & 4.3 & 8.2 & 4.7 & 6.4 & 4.1 & 4.7 & 3.4 \\
$N$ & 428 & & 133 & & 126 & & 169 & \\
& & & & & & & &
\end{tabular}


Italian subsample standing in-between (6.4\%). As for Social protection, Greek $(10.3 \%)$ and Italian $(11.7 \%)$ respondents showed lower preferences than the Swiss $(13.9 \%)$.

However, since allocations are sometimes close to each other, one may still wonder if individuals were able to discriminate between the relative usefulness or utility of each task and to allocate budget resources accordingly. To investigate this issue and answer our RQ1, we carried out a pair-wise test of difference of means to find out if respondents were able or willing to express a difference between two FOGs that are otherwise close in terms of the allocated amounts. For example from Table 1, Greek respondents allocated the largest share of the hypothetical budget to Health (17.8\%) and the second largest to Education (17.1\%). The question is thus to know if respondents are really declaring significantly different preferences between Health and Education. Or if the difference is just insignificant and therefore respondents were either indifferent between the two FOGs or were just cognitively unable to state a difference (although a difference may truly exist in their mind).

Table 2 presents the results of the pairwise comparisons of means. In each column, FOGs sharing a letter show means that are not significantly different at the $5 \%$ level. The test of equality of means gauges the null-hypothesis that the amounts allocated to each FOG are on average statistically identical over the considered pair of FOG. If the null-hypothesis is rejected it means that in general (i.e. over the whole sample) respondents allocated the budget unevenly, that is with discrimination. For instance, Health and Education share the letter A in the Greek case. Indeed, the test shows that the average of the allocations to these two functions is not different. Overall, the means cannot be considered to be different in the following cases: Health and Education (1), Economic affairs and Environmental protection (2), Environmental protection and Public order and safety (3), General public services and Recreation, culture and religion (4), Recreation, culture and religion, and Defense (5). In contrast, the means of allocations within all other pairs of FOGs are clearly different. For instance, the average allocation to Education, Health or Social protection is statistically higher than the average allocation to General public services, Recreation, culture and religion or Defense. This provides a positive answer to RQ1: Individuals are able to discriminate their allocation between the various governmental tasks, although mean allocations may be similar for some functions.

Table 2 also shows whether preferences were mostly homogeneous or mostly heterogeneous, according to respondents in the three different country subsamples. Or, to put it another way, in which subsample respondents most differentiated between the $10 \mathrm{FOGs}$.

\begin{tabular}{|c|c|c|c|c|c|c|c|c|}
\hline \multirow[b]{2}{*}{ Function } & \multicolumn{2}{|c|}{ Overall } & \multicolumn{2}{|c|}{ Greek } & \multicolumn{2}{|c|}{ Italian } & \multicolumn{2}{|c|}{ Swiss } \\
\hline & Mean & Groups & Mean & Groups & Mean & Groups & Mean & Groups \\
\hline Education & 16.3 & $\mathrm{~A}$ & 17.1 & $\mathrm{~A}$ & 15.3 & & 16.3 & \\
\hline Health & 16.0 & $\mathrm{~A}$ & 17.8 & A & 16.5 & & 14.3 & $\mathrm{~A}$ \\
\hline Social protection & 12.2 & & 10.3 & $\mathrm{~B}$ & 11.7 & $\mathrm{~A}$ & 13.9 & $\mathrm{~A}$ \\
\hline Economic affairs & 9.6 & $\mathrm{~B}$ & 9.7 & $\mathrm{BC}$ & 9.1 & $\mathrm{~B}$ & 10.0 & \\
\hline Environmental protection & 9.2 & $\mathrm{BC}$ & 8.1 & $\mathrm{DE}$ & 10.6 & $\mathrm{AC}$ & 9.0 & $\mathrm{~B}$ \\
\hline Public order and safety & 8.8 & $\mathrm{C}$ & 8.9 & $\mathrm{DC}$ & 10.1 & $\mathrm{BC}$ & 7.8 & $\mathrm{C}$ \\
\hline $\begin{array}{l}\text { Housing and community } \\
\text { amenities }\end{array}$ & 8.2 & & 7.7 & $\mathrm{E}$ & 7.5 & $\mathrm{D}$ & 9.1 & $\mathrm{~B}$ \\
\hline General public services & 7.0 & $\mathrm{D}$ & 6.1 & $\mathrm{~F}$ & 7.4 & $\mathrm{D}$ & 7.4 & $\mathrm{C}$ \\
\hline Recreation, culture and religion & 6.4 & $\mathrm{DE}$ & 6.1 & $\mathrm{~F}$ & 5.4 & $\mathrm{E}$ & 7.4 & $\mathrm{C}$ \\
\hline Defense & 6.3 & $\mathrm{E}$ & 8.2 & $\mathrm{DE}$ & 6.4 & $\mathrm{DE}$ & 4.7 & \\
\hline$N$ & 428 & 5 & 133 & 6 & 126 & 5 & 169 & 3 \\
\hline Spread maximum-minimum & 10.0 & & 11.7 & & 11.1 & & 11.6 & \\
\hline
\end{tabular}

Note(s): In each column, functions sharing a letter show means that are not significantly different at the $5 \%$ level$$
\text { putitanother, way, in which subsamplerespondents most differentiated between the 10FOGs. }
$$

Allocating government budgets

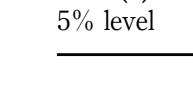

政 
In that respect, the figures for Greece indicate the highest number of pairs without significant differences between the means: A to F, that is six pairs. Italy and Switzerland follow with five and three pairs. Indeed, Swiss respondents' average preferences were somehow more clear-cut. However, the spread between the top and the bottom rank values was 11.7 percentage points in the Greek subsample, 11.1 in the Italian one and 11.6 in the Swiss one.

Table 3 further investigates if respondents really made a cognitive effort to discriminate between FOGs when allocating units. Mitchell and Carson (1989) stress that respondents may "adopt strategies to lighten the task" when answering requires a significant effort (p. 240). In our case, respondents were prompted to allocate 100 units to 10 functions. These figures may have implied value clues and thus biased the allocation formation or the allocation statement process. Such bias can be likened to an "anchoring effect". For instance, if wanting to minimize effort, respondents could have divided the budget of 100 units uniformly and allocated an identical value of 10 to each function. This would imply that the value 10 would have been used with an overwhelming frequency and that any given function would have been allocated the value 10 with an almost even frequency. A "lazy" respondent may also have allocated the total budget (100) to one function and no budget to the other ones (0).

The table presents the number of times a particular value was used. The considered range of values is: $0,5,10,15,20,30,40,50$ and 60 (60 being the highest reported allocation). Table 3 shows that no respondent took the "lazy" strategy (frequency of value $100=0 \%$ ). The value of 0 was used 99 times, however, it was used for functions that, on average, were granted low allocations overall.

The value of 10 units was allocated 1,092 times, with a frequency varying between 150 (Public order and safety) and 74 (Health). This frequency represents slightly more than a quarter of the answers ( $26 \%$ of the 4,280 allocations given by the 428 respondents to the 10 FOGs). Values close to 10, for instance 9 or 11, were allocated much less frequently. They represent a bit more than $1 \%$ of the stated values (figure not included in Table 3). Note that a frequency of $1 \%$ is what would be expected for a purely random allocation. Values of 5 and 15 units were also used quite frequently ( 20 and $11 \%$, respectively).

The values 0,5 or 10 were less frequently used for those functions granted the highest values on average, i.e. Education and Health. This suggests that when preferences are clear-cut, the anchoring effect is less powerful. However, for these FOGs, respondents seem to have favored higher values (15 or 20 ).

The same pattern seems to apply, although in reverse, to the FOGs that received the lowest average allocations, that is Recreation, culture and religion and Defense. Here the values 10 and above were less frequently used, whereas anchors below 10 were more frequently used.

Table 3.

Frequency of respondent allocations depending on the considered anchors

\begin{tabular}{lrrrrrrrrr}
\hline & \multicolumn{10}{c}{ Frequency depending on the anchor } \\
Function & \multicolumn{1}{c}{5} & \multicolumn{1}{c}{10} & 15 & 20 & 30 & 40 & 50 & 60 \\
\hline Education & 1 & 4 & 79 & 98 & 103 & 11 & 0 & 1 & 1 \\
Health & 1 & 5 & 74 & 108 & 95 & 17 & 2 & 0 & 0 \\
Social protection & 6 & 39 & 130 & 86 & 43 & 1 & 1 & 0 & 0 \\
Economic affairs & 12 & 83 & 121 & 47 & 28 & 1 & 0 & 0 & 0 \\
Environmental protection & 2 & 84 & 147 & 32 & 11 & 2 & 0 & 1 & 0 \\
Public order and safety & 6 & 87 & 150 & 36 & 11 & 1 & 0 & 0 & 0 \\
Housing and community amenities & 12 & 105 & 138 & 21 & 6 & 0 & 0 & 0 & 0 \\
General public services & 22 & 140 & 96 & 10 & 7 & 1 & 0 & 0 & 0 \\
Recreation, culture and religion & 13 & 162 & 77 & 8 & 5 & 0 & 0 & 0 & 0 \\
Defense & 24 & 139 & 80 & 20 & 7 & 0 & 0 & 0 & 0 \\
Total & 99 & 848 & 1,092 & 466 & 316 & 34 & 3 & 2 & 1 \\
\% of all 4,280 allocations & 2 & 20 & 26 & 11 & 7 & 1 & 0 & 0 & 0 \\
\hline
\end{tabular}


The uneven distribution of the frequencies of the allocated values suggests that the results are not biased by an anchoring effect. The results rather denote a tendency to round off the allocation. The allocations rounded to multiples of five in the range of $5-15$ represent $57 \%$ of the answers, meaning that higher rounded values (i.e. above 15) and other - non-rounded values are also frequently used. Thus, this evidence of a rounding off rather than an anchoring phenomenon suggests that individuals, although they made efforts to discriminate their allocation, did not find it easy to be very precise. Nevertheless, the rounding off is not strong enough to bias the ranking of the FOGs and to obliterate differences in intensity of individual preferences. This brings a rather positive answer to RQ2 and is in line with Loomes' findings (1988): Individuals avoid lightening their task by anchoring their answers to some piece of information provided by the questionnaire, although they tend to round the elicited values.

Nevertheless, it has to be acknowledged that the actual allocation of funds among the FOGs in the three countries differs from respondent allocations (Table 4). Table 4 shows, next to the mean of the elicited allocation preferences, how actual expenditures are distributed among the FOGs. Data come from Eurostat and refer to 2015. They are for the general government, that is for the central government, the state governments, the local governments and the social security. These data provide an external benchmark to the survey. Thus they make it possible to test the external validity of the contingent allocation.

Table 4 displays some similarities in terms of the ranking of the FOGs according to the allocated values in the study and the actual values spent by governments. It also shows some considerable differences. When measured in units, what respondents allocate to Social protection appears much lower than what the general governments actually spend: overall 12.2 compared to 39.8. General public services follow the same pattern with a mean reported allocation of 7.0 compared to an actual allocation of 15.7. The same applies, although to a lesser extent, to Economic affairs (9.6 compared to 11.7). This finding explains why respondents can then allocate a larger budget to the seven remaining functions compared to what is actually spent. The results are quite similar among subsamples. Differences between values allocated by respondents and actual values are salient, even in the case of functions that are currently granted the largest share of the government's budget. Therefore, the elicited preferences are inconsistent with current budget allocations or vice-versa. Various interpretations can be given to these differences. Before providing any possible explanations,

\begin{tabular}{lrrrrrrrr}
\hline & \multicolumn{2}{c}{ Overall $^{*}$} & \multicolumn{2}{c}{ Greek } & \multicolumn{2}{c}{ Italian } & \multicolumn{2}{c}{ Swiss } \\
Function & Mean & Actual $^{\mathrm{a}}$ & Mean & Actual & Mean & Actual & Mean & Actual \\
\hline Education & 16.3 & 11.0 & 17.1 & 7.8 & 15.3 & 7.9 & 16.3 & 17.2 \\
Health & 16.0 & 9.6 & 17.8 & 8.2 & 16.5 & 14.1 & 14.3 & 6.5 \\
Social protection & 12.2 & 39.8 & 10.3 & 37.1 & 11.7 & 42.6 & 13.9 & 39.8 \\
Economic affairs & 9.6 & 11.7 & 9.7 & 16.0 & 9.1 & 8.1 & 10.0 & 11.0 \\
Environmental protection & 9.2 & 2.2 & 8.1 & 2.7 & 10.6 & 1.9 & 9.0 & 2.1 \\
Public order and safety & 8.8 & 4.2 & 8.9 & 3.8 & 10.1 & 3.7 & 7.8 & 5.0 \\
Housing and community & 8.2 & 0.7 & 7.7 & 0.4 & 7.5 & 1.2 & 9.1 & 0.6 \\
amenities & & & & & & & & \\
General public services & 7.0 & 15.7 & 6.1 & 17.8 & 7.4 & 16.6 & 7.4 & 12.6 \\
Recreation, culture and religion & 6.4 & 1.7 & 6.1 & 1.3 & 5.4 & 1.5 & 7.4 & 2.4 \\
Defense & 6.3 & 3.4 & 8.2 & 4.9 & 6.4 & 2.4 & 4.7 & 2.8
\end{tabular}

Note(s): Mean: Authors' survey; Actual: Eurostat data base (central government expenditure by function (COFOG), sector general government)

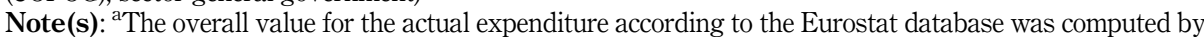
the authors as the unweighted average of the shares in all three subsamples

\section{Allocating government budgets}

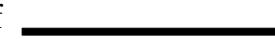


it has to be stressed that a convenient sampling was used and that the results do not pledge representativity. If representativity is taken for granted (which is obviously not the case), then a further interpretation would be that results exhibit the divergences in priorities between the government and the citizens. For example, citizens would prefer not to allocate a large amount of money to general public services, something which includes, among other things, payments for public debt. They may prefer instead to invest resources in better health conditions and improved education. A more drastic interpretation would be that respondents did not fully consider the implication of their allocation either because they were not able to or because they chose not to. This interpretation would raise doubts about the rationality of the stated preferences. However, answers provided to RQ1 and RQ2 already suggest that some rationality frames the results.

\section{Modeling respondent allocations}

Further testing of respondent rationality and answering RQ3 required a more detailed, individually based, analysis. We had to determine whether certain individual characteristics might affect respondent allocations. If some characteristics did have a significant impact, this would suggest that the budget was not, or at least not fully, randomly allocated and that part of the allocation was somehow rational. More specifically, we had to test whether respondent personal profile and the country subsample correlated with the allocation.

The design of the experiment requires the use of the seemingly unrelated regression model (SUR) proposed by Zellner (1962). Here, the model consists of 10 regression equations, each having as dependent variable the value allocated $A$ to a specific function $f$ and the same set of explanatory variables $X$. We specifically control for the respondent's country subsample using a categorical variable, $G$ in case the respondent was Greek and $I$ when the respondent was Italian. The subsample variable encapsulates and surrogates a plethora of characteristics that refer to the existing differences between country context, cultural preferences, perceived threats and opportunities such as exposure to immigration, tensions with bordering countries. We also specifically controlled for the fact that the respondent or her/his relatives might be employed $E$ in one of the government's functions. In that case, the budget-maximizing model predicts that the rational bureaucrat should try to increase her/his budget in order to increase her/his own power (Niskanen, 1971); thus a positive correlation is expected. As set out in a SUR model, the disturbance terms $\varepsilon$ are assumed to be correlated across the equations. Thus the model to be estimated was as follows:

$$
A_{f r}=\alpha_{f}+\beta_{f} G_{f r}+\varphi_{f} I_{f r}+\tau_{f} E_{f r}+\gamma_{f} X_{f r}+\varepsilon_{f r}
$$

where $f$ represents the equation number for a specific function $(f=1, \ldots 10)$ and $r$ is the respondent. $\alpha, \beta, \varphi, \tau$ and $\gamma$ are the coefficients associated to the constant term and to the explanatory variables. The model was estimated simultaneously using the asymptotically efficient, feasible, generalized least-squares (FGLS).

Explanatory variables were constructed using respondents' answers to the questionnaire. Table 5 lists the explanatory variables. Variables are grouped into three categories. The first category consists of a categorical variable that reflects the subsample. If it turns out to be significant, the variable would indicate how the allocation of Greek or Italian respondents diverges from their Swiss counterparts.

The second category brings together variables dedicated to Public Service propinquity, including the cases in which the respondent or relatives thereof were employed in the corresponding function. As for the political position, following Papadakis and Bean (1993), one may obviously expect that respondents with a more right-oriented opinion allocate comparatively less to welfare, and especially to Social protection and to Housing. Being or having been a member of a legislative body or of a government's executive branch may 


\begin{tabular}{ll}
\hline Variable & Description \\
\hline $\begin{array}{l}\text { Country } \\
\text { subsample }\end{array}$ & $\begin{array}{l}\text { Categorical variable with } 2 \text { dummies: Respondent belongs to the Greek subsample }(G) \text { or } \\
\text { to the Italian }(I) \text {. The baseline when Greek }=0 \text { and Italian }=0 \text { is when the respondent } \\
\text { belongs to the Swiss subsample }\end{array}$
\end{tabular}

Public sector propinquity

In the function Respondent or relatives are employed in the corresponding function. Variable specific to each of the ten equations. For example, it takes the value 1 in the equation explaining Education if just the respondent has worked in that domain and it takes the value 0 in the 9 other equations. It also takes just the value 1 if a respondent's relative has worked in the function. It takes the value 2 if both the respondent and at least one of her relatives have worked in the function. For another respondent, it takes the value 1 or 2 in the equation explaining Health if this respondent and/or at least one of her relatives have been employed in the health sector and it takes the value 0 in other equations (including the Education equation); etc.

Political position How respondents place their views in political matters on a scale between 1 (the farthest left position) and 10 (the farthest right position). Ordinal variable

Legislature Ordinal variable: 2 = respondent is currently member of a legislative body of a government, either at the national, regional or local level; 1 = respondent had been a member of such a legislative body in the past; $0=$ respondent has never been a member of a legislative body

Executive

Ordinal variable: 2 = respondent is currently member of an executive branch of a government, either at the national, regional or local level; 1 = respondent has been a member of such an executive branch in the past; $0=$ respondent has never been a member of an executive branch

Socioeconomic characteristics

Age

Gender

Social class

Age of the respondents. Discrete variable

(1)

Men or women. Binary variable: woman $=1$; $\operatorname{man}=0$

Class to which the respondent says her/his household belongs. Ordinal variable:

$1=$ working class; $2=$ lower middle class; $3=$ middle class; $4=$ upper middle class ;

$5=$ higher class

Education

Respondents that say they have followed a general or academic education at the end of compulsory education. Binary variable: $1=$ yes, $0=$ no

Religion

Categorical variable with two dummies: Christian, Other religion. Respondent with no religion is the baseline when Christian $=0$ and Other religion $=0$

Partner

Children

\section{Allocating government budgets}

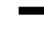


respondent's interest in politics, income, number of people aged 15 and above in the household, degree of urbanization of the place of residence. Table 6 provides the usual summary statistics regarding the retained explanatory variables. The issue of a possible multicollinearity between explanatory variables was investigated by computing the variance inflation factors (VIF) and no sign of such problem appeared [5].

Table 7 shows the results of the analysis for each of the 10 estimated equations. The model is based on 380 observations for which we have the information regarding all variables. The general finding was that only a few of the hypothesized explanatory variables were statistically significant and that these variables explain only a fraction of budget allocation variance with the R-squared varying between 6 and $20 \%$. At first glance, this performance could be regarded as modest. However, considering the existing studies that have used contingent valuation and a sample of similar size, being able to explain a tenth or a fifth of the dependent variable's variance is acceptable. Furthermore, the $\mathrm{Chi}^{2}$ test shows that the estimated model is jointly significant for all functions, except for General public services, which is not surprising since the latter function is highly heterogeneous [6]. The fact that some variables were significantly correlated with the allocation provides evidence that the respondents did not allocate the budget randomly. Therefore, the allocation presents some internal validity. The values allocated to Public order and safety or Defense were those that correlated with the largest number of explanatory variables (5). The lowest number (of explanatory variables) was found in four equations (Education; Housing and community; General public services; Recreation, culture and religion). Considering the different variables, the country subsample correlated significantly with the largest number of equations (in four equations for the Greek dummy and in seven for the Italian). For instance, Greek respondents allocated three additional units to Health and Defense compared to the Swiss (the baseline for

\begin{tabular}{|c|c|c|c|c|c|}
\hline Explanatory variables & Mean & $\mathrm{SD}$ & Min & $\operatorname{Max}$ & $\mathrm{N}$ \\
\hline Greek & 0.31 & 0.46 & 0 & 1 & 428 \\
\hline Italian & 0.29 & 0.46 & 0 & 1 & 428 \\
\hline \multicolumn{6}{|l|}{ In the function... } \\
\hline ... Education & 0.28 & 0.50 & 0 & 2 & 424 \\
\hline ... Health & 0.15 & 0.38 & 0 & 2 & 424 \\
\hline ... Social protection & 0.07 & 0.27 & 0 & 2 & 424 \\
\hline ... Economic affairs & 0.13 & 0.38 & 0 & 2 & 424 \\
\hline ... Environmental protection & 0.02 & 0.15 & 0 & 1 & 424 \\
\hline ...P Public order and safety & 0.06 & 0.24 & 0 & 1 & 424 \\
\hline ... Housing and community amenities & 0.03 & 0.17 & 0 & 1 & 424 \\
\hline ... General public services & 0.32 & 0.52 & 0 & 2 & 424 \\
\hline ... Recreation, culture and religion & 0.04 & 0.22 & 0 & 2 & 424 \\
\hline ... Defense & 0.04 & 0.22 & 0 & 2 & 424 \\
\hline Political position & 5.16 & 2.07 & 1 & 10 & 401 \\
\hline Legislature & 1.14 & 0.47 & 1 & 3 & 420 \\
\hline Executive & 1.28 & 0.67 & 1 & 3 & 419 \\
\hline Age & 34.01 & 11.19 & 20 & 64 & 410 \\
\hline Gender & 0.53 & 0.50 & 0 & 1 & 419 \\
\hline Social class & 3.10 & 0.72 & 1 & 5 & 420 \\
\hline Education & 0.91 & 0.29 & 0 & 1 & 416 \\
\hline Christian & 0.63 & 0.48 & 0 & 1 & 425 \\
\hline Other religion & 0.03 & 0.16 & 0 & 1 & 425 \\
\hline Partner & 0.41 & 0.49 & 0 & 1 & 421 \\
\hline Children & 0.37 & 0.75 & 0 & 4 & 415 \\
\hline
\end{tabular}

Table 6.

Descriptive statistics 
this categorical variable). Italians also allocated more to these two functions as well as to Environmental protection and to Public order and safety (about two additional units each). Greek respondents indicated lower preferences for Social protection (almost -4 ) and for General public services ( -1 ). So did Italians also for Social protection (almost -3 ) and for both Housing and community amenities and Recreation, culture and religion (around -2 each). These findings indicate that subsample and possibly national context affect the way citizens would allocate government monies. In other words, the analysis provides corroborative evidence that there is not a unanimous optimal way of allocating a governmental budget that could be measured by consulting citizens and then applied in the form of a best practice to all countries.

The information conveyed by the in the function variable is particularly interesting. According to the budget-maximizing model, when respondents (or their relatives) are employed in a given function, they can be expected to allocate a higher share of the budget to that function. Our results contradict this expectation. While the coefficient of the corresponding variable was positive in eight out of the ten equations, it was never statistically significant. Therefore, in this specific case the findings tend to contradict the self-interest axiom of most public choice literature contributions (Widerquist, 2003).

The political position often correlated at a statistically significant level with the allocations, and the coefficients usually had the expected sign. Respondents considering their political views closer to the right tended to allocate more to Economic affairs. A one-point move rightwards along the 1-to-10 political position scale triggered a 0.4 unit increase in the stated amount. The same move reduced the allocation to Social protection $(-0.5)$, Housing and community amenities $(-0.2)$ and Recreation, culture and religion $(-0.2)$.

Being or having been a member of a legislative body also induced different preferences from the average survey respondent. Members of legislative bodies allocated more to Environmental protection and less to Public order and safety and to Defense. As for those that have served or are currently serving on a government's executive branch, they allocated more budget resources to education.

The respondents' socioeconomic characteristics correlated sporadically with the allocations, except for social class and education. For most of them, the sign of the estimated coefficient could hardly be interpreted. It should be noted, however, that, logically enough, the number of children correlated positively with the Education allocation and negatively with the allocation to Social protection.

Based on the results of the SUR model and in response to RQ3, respondent answers follow some rational pattern that can at least be partially approximated by some personal and country characteristics. The country subsample significantly influences respondent allocations to most of the functions. Respondents belonging either to the Greek or the Italian subsamples allocated substantially different amounts compared to the Swiss subsample. Moreover, other variables related to personal characteristics and beliefs correlated with the reported amount. This supports the view that the preferences stated by survey participants, through their allocations, are internally valid (at least partially). The fact that the explanatory power is not larger may be imputable to the rounding phenomenon we mentioned above, that is to an imprecise measurement of the dependent variable. It may also be attributable to some unsurveyed explanatory variables or to some degree of randomness in the allocation. However, this answer to RQ3, together with the answers to RQs 1 and 2 , enables us to respond negatively to our main research question: Individuals do not state their allocation purely randomly.

\section{Conclusion}

This cross-national study is an innovative contribution to the literature on participative approaches in government. It investigates if, when asked to state their preferences for the 
allocation of public monies toward broad governmental functions, individuals state them at random or, on the contrary, if their choice follows some rational pattern that can be traced using explanatory variables. Methodologically, this study adapts the basic idea of the CVM so that respondents, by filling in a survey instrument, are given the power to allocate public funds according to their views. Given the exploratory nature of the study, the questionnaire was administered to a convenient sample in three countries: Greece, Italy and Switzerland. Respondents, all citizens of an age to vote and pay taxes, were civil servants, entrepreneurs, head teachers or students participating in Masters and advanced studies courses in public administration, management, economics, accounting, finance. The 428 persons who agreed to participate in the contingent allocation process were surveyed between February 2016 and July 2017.

Regarding our research questions, respondents seemed to discriminate between the relative usefulness of most of the tasks and to allocate budget resources accordingly, even if they may have resorted to some rounding off practices. The study also investigated whether personal characteristics and the country context as reflected in the country subsamples influenced the way individuals allocated budget resources between government functions. The regression analysis shows that the country subsample significantly influenced respondent allocations to various functions (health, social, and environmental protection, public order and safety, housing, culture, defense). Moreover, depending on the function, some other variables correlated with the reported amount, for instance the respondent's positions on political matters, the fact that the respondent was or had been a member of a legislative body or of the executive branch, or whether they had children. Therefore, preferences were not randomly stated in the survey and allocations have some internal validity. Having said that, the models, albeit partially, explain how respondents allocate the budget. Other explanatory variables than those which were collected and tested might correlate with allocations. Finding those variables is definitely an avenue for future research. A set of explanatory variables proved not to be significantly correlated with the allocated amounts (i.e. respondent's interest in politics, income, number of people aged 15 and above in the household, degree of urbanization of the place of residence). Interestingly, respondents who were employed in a government function - or whose relatives were employed in a function - did not allocate more to that function.

While it is clear that these empirical results reflect the preferences of the sample and not the whole population in any of the three countries covered in our study, and the sample size prevents a generalization of the findings, at the same time it is undeniable that Education, Health and Social protection received the largest share of the respondents' contingent budget, reflecting, in an ordinal way, citizen preferences. From a policy perspective, understanding citizen preferences in budget allocation may help governments rationalize the spending of public money. Moreover, this study may also provide a useful starting point for the expansion of the use of participatory budgeting, not only at the level of local governments and for very limited projects but also to lay new foundations for a broader debate on budget allocations at higher levels of government.

\section{Notes}

1. Individuals may of course place the same allocations on some governmental tasks. This would not imply that they are irrational. There is always the possibility of being indifferent between some governmental tasks. However, not being able to somehow discriminate the allocations between all the tasks a government has to perform would lead to the conclusion that individuals are indifferent between all governmental tasks or, put differently, that all governmental tasks provide individuals the same utility. Such a situation is hardly conceivable. Therefore, differences between some allocations are expected.

\section{Allocating government budgets}


2. For example "Social protection" had the following description: Sickness and disability; Old age; Survivors; Family and children; Unemployment; Housing; Social exclusion; R\&D in this area, while "General Public Services" was explained as including: Executive and legislative organs, financial and fiscal affairs, external affairs; Foreign economic aid; General services; Basic research; R\&D in this area; Public debt transactions; Transfers of a general character between different levels of government. The depiction corresponds to the one given in the COFOG manual (European Union, 2019, p. 37).

3. The questionnaire in all four languages and the database are available upon request from the authors.

4. Despite the fact that data gathering took place at different times and places, there was not any important incident before the administration of the questionnaire that would bias respondents toward a specific allocation preference.

5. All variance inflation factors (VIF) are by far smaller than 10 (see Appendix).

6. Cf. Footnote 2 for a depiction of the various activities this function encompasses.

\section{References}

Arrow, K., Solow, R., Portney, P., Leamer, E., Radner, R. and Schuman, H. (1993), "Report of the national oceanic and atmospheric administration (NOAA) panel on contingent valuation", Federal Register, Vol. 58, pp. 4601-4614.

Bondonio, P. and Marchese, C. (1994), "Equilibrium in fiscal choices: evidence from a budget game", Public Choice, Vol. 78 No. 3-4, pp. 205-218.

Carlin, T.M. (2003), Suspicion where Suspicion Is Due: Myths and Rhetoric in the Accrual Budgeting Tale, Macquarie Graduate School of Management, Sydney, Working Paper 2003-25.

Carson, R.T. (2011), Contingent Valuation: A Comprehensive Bibliography and History, Edward Elgar, Cheltenham.

Carson, R.T. (2012), “Contingent valuation: a practical alternative when prices aren't available”, The Journal of Economic Perspectives, Vol. 26 No. 4, pp. 27-42. doi: 10.1257/jep.26.4.27.

Champ, P.A., Boyle, K.J. and Brown, T.C. (Eds) (2003), A Primer on Nonmarket Valuation. Vol. 3 of The Economics of Non-Market Goods and Resources, Kluwer Academic Publishers, Dordrecht.

Dabla-Norris, E., Allen, R., Zanna, L.F., Prakash, T., Kvintradze, E., Lledo, V. and Gollwitzer, S. (2010), "Budget institutions and fiscal performance in low-income countries", IMF working papers, pp. 1-56.

Dahl, R.A. (1971), Polyarchy: Participation and Opposition, Yale University Press, New Haven, CT.

Downs, A. (1957), An Economic Theory of Democracy, Harper and Row, New York.

European Union (2019), Manual on Sources and Methods for the Compilation of COFOG Statistics. Classification of the Functions of Government (COFOG), 2019 ed., Publications Office of the European Union, Luxembourg.

Hausman, J. (2012), "Contingent valuation: from dubious to hopeless", The Journal of Economic Perspectives, Vol. 26 No. 4, pp. 43-56, doi: 10.1257/jep.26.4.43.

Kerr, G.N., Cullen, R. and Hughey, K.F.D. (2010), "Choice experiment assessment of public expenditure preferences”, New Zealand Economic Papers, Vol. 44 No. 3, pp. 259-268, doi: 10.1080/00779954. 2010.522163.

Key, V.O. (1940), "The lack of a budgetary theory", American Political Science Review, Vol. 34 No. 6, pp. 1137-1144.

Layard, R. (1972), Cost -Benefit Analysis: Selected Readings, Penguin Books, Harmondsworth.

Lewis, V.B. (1952), "Toward a theory of budgeting”, Public Administration Review, Vol. 12 No. 1, pp. $42-54$. 
Loomes, G. (1988), "Different experimental procedures for obtaining valuations of risky actions: implications for utility theory", Theory and Decision, Vol. 25 No. 1, pp. 1-23.

McNutt, P.A. (1996), The Economics of Public Choice, Cheltenham/Brookfield, Edward Elgar.

Mitchell, R.C. and Carson, R.T. (1989), Using Surveys to Value Public Goods: The Contingent Valuation Method, Resources for the Future, Washington DC.

Niskanen, W.A. (1971), Bureaucracy and Representative Government, Aldine-Atherton, New York.

Papadakis, E. and Bean, C. (1993), "Popular support for the welfare state: a comparison between institutional regimes", Journal of Public Policy, Vol. 13 No. 3, pp. 227-254.

Robbins, M.D. and Simonsen, W. (2002), "A dynamic method of citizen. Preference revelation”, Journal of Public Budgeting, Accounting and Financial Management, Vol. 14 No. 3, pp. 445-461.

Rowe, G. and Frewer, L.J. (2005), “A typology of public engagement mechanisms”, Science, Technology and Human Values, Vol. 30 No. 2, pp. 251-290, doi: 10.1177/0162243904271724.

Royo, S., Yetano, A. and Acerete, B. (2011), "Citizen participation in German and Spanish local governments: a comparative study", International Journal of Public Administration, Vol. 34 No. 3, pp. 139-150, doi: 10.1080/01900692.2010.533070.

Simonsen, W. and Robbins, M.D. (2000), Citizen Participation in Resource Allocation, Westview Press, Boulder, CO.

Smith, G. (2005), Beyond the Ballot: 57 Democratic Innovations from Around the World, Power Inquiry, London.

Soroka, S.N. and Wlezien, C. (2010), Degrees of Democracy: Politics, Public Opinion, and Policy, Cambridge University Press, New York.

Walters, L.C., Aydelotte, J. and Miller, J. (2000), "Putting more public in policy analysis", Public Administration Review, Vol. 60 No. 4, pp. 349-359.

Wampler, B. (2007), “A guide to participatory budgeting”, in Shah, A. (Ed.), Participatory Budgeting, Public Sector Governance and Accountability Series, The World Bank, Washington, DC.

Welch, E.W., Hinnant, C.C. and Moon, M.J. (2004), "Linking citizen satisfaction with e-Government and trust in government", Journal of Public Administration Research and Theory, Vol. 15 No. 3, pp. 371-391, doi: 10.1093/jopart/mui021.

Widerquist, K. (2003), "Public choice and altruism", Eastern Economic Journal, Vol. 29 No. 3, pp. 317-337.

Wildavsky, A. (1961), "Political implications of budgetary reform", Public Administration Review, Vol. 21 No. 4, pp. 183-190.

Zellner, A. (1962), "An efficient method of estimating seemingly unrelated regressions and tests for aggregation bias", Journal of the American Statistical Association, Vol. 57, pp. 348-368. 


\section{Appendix}

\begin{tabular}{lr}
\hline Explanatory variables & VIF \\
\hline Greek & 1.96 \\
Italian & 1.56 \\
In the function... & 1.22 \\
.. Education & 1.07 \\
.. Health & 1.11 \\
.. Social protection & 1.06 \\
.. Economic affairs & 1.21 \\
.. Environmental protection & 1.09 \\
.. Public order and safety & 1.20 \\
.. Housing and community amenities & General public services \\
.. Recreation, culture and religion & 1.27 \\
.. Defense & 1.08 \\
Political position & 1.12 \\
Legislature & 1.21 \\
Executive & 1.15 \\
Age & 1.42 \\
Gender & 1.89 \\
Social class & 1.15 \\
Education & 1.20 \\
Christian & 1.16 \\
Other religion & 1.19 \\
Partner & 1.12 \\
Children & 1.86 \\
Mean VIF & 1.32 \\
Note(s): Multicollinearity may be an issue when the VIF is equal to or higher than 10 & 1.29 \\
& \\
\hline
\end{tabular}

\section{Corresponding author}

Sandra Cohen can be contacted at: scohen@aueb.gr

For instructions on how to order reprints of this article, please visit our website:

www.emeraldgrouppublishing.com/licensing/reprints.htm

Or contact us for further details: permissions@emeraldinsight.com 